\title{
A saúde na escola: um breve resgate histórico
}

\author{
Health at school: a brief history
}

Túlio Alberto $M$ artins deFigueiredo ${ }^{1}$

Vera Lúcia Taqueti M achado ${ }^{2}$

M argaret M irian Scherrer de Abreu ${ }^{2}$

${ }^{1}$ Centro deCiências da Saúde, UniversidadeFederal do Espírito Santo. Av. $M$ arechal Campos 1468 Maruípe. 29040-090 Vitória ES.

tulioamf@npd.ufes.br ${ }^{2}$ Secretaria M unicipal de SaúdedeVitória.

Abstract It involves the historical birth of school health in the world and Brazil. It shows a regional initiative of $\mathrm{H}$ ealth Promoting Schools - a discourse of multipleviewings and joint work among education, health and society - , as an alternative model of attention to school health, recommended by Pan American H ealth O rganization, to the Caribbean and Latin American Countries. Finally, it takes into account that a detailed observation of the National Curriculum Parameters is an essential condition so that health professionals, who are sensitive to the school health education issue, can contribute to its inclusion in the fundamental education with a critical, interdisciplinary and transversal approach, presenting the guidelines of a new national health polices at public schools.

Key words School health, Health Promoting Schools, Health promotion
Resumo Discute o nascimento histórico da saúde escolar no mundo e no Brasil. Apresenta a Iniciativa Regional Escolas Promotoras de Saúde um discurso de múltiplos ol hares e trabalho articulado entrea educação, saúdee sociedade- , como modelo alternativo de atenção à saúde na escola recomendado, pela Organização Pan-Americana de Saúde, para os países do Caribe e da América Latina. Considera que o olhar atento aos Parâmetros Curriculares Nacionais é condição fundamental para que os profissionais de saúde sensíveis à questão da educação em saúde na escola contribuam para quea mesma compareça na educação fundamental com um enfoque crítico, interdisciplinar e transversal e, finalmente, apresenta as diretrizes da nova política nacional de saúde na escola pública.

Palavras-chave Saúde escolar, Escolas Promotoras de Saúde, Promoção à saúde 
O nascimento (histórico) da saúdena escola

Os avatares da política de atenção à saú de escolar remontam o final do século XVIII e o início do século XIX, quando o médico alemão Johann Peter Frank (1745-1821) elaborou o System einer Vollständigen Medicinischen Politizei que ficou conhecido posteriormente como Sistema Frank.

O Sistema Frank foi um guia publicado na Alemanha, a partir de 1779, em nove volumes (sendo os dois últimos póstumos). $\mathrm{N}$ a avaliação de Rosen ${ }^{1}$, "este trabalho hoje é considerado um marco no pensamento a respeito das relações sociais da saúde e da doença". O Sistema Frank contemplava não apenas a saúde escolar, mas, também, múltiplos aspectos da saúde pública e individual, tais como demografia, casamento, procriação, puerpério, saúde infantil, medicina militar, doenças infecto-contagiosas, vestuário, esgotos, suprimento de água e prevenção de acidentes ${ }^{2}$. Enfim, tal guia deveria mesmo ser abrangente, visto que foi escrito sob a inspiração do pensamento político e econômico vigente no final do século XVII e início da maior parte do século XVIII, na Alemanha, no qual, segundo Heckscher, citado por Rosen, foi "marcante a admiração pelas virtudes de uma população crescente e 0 intenso desejo de aumentar o número de habitantes de um país"1.

A referida obra - o Sistema Frank -, legou a Johan Peter Frank o reconhecimento como o pai da saúde escolar visto que, no tocante ao tema, [...] dispunha detalhadamentesobreo atendimento escolar e a supervisão das institui ç̧ões educacionais particularizando desde a prevenção de acidentes até a higi ene mental, desde a elaboração de programas de atletismo até a iluminação, aquecimento e ventilação das salas de aula"2.

O Sistema Frank resultou na proposição de um código elaborado por Franz Anton M ai. Rosen $^{1}$ observa que " $M$ ai estava totalmente familiarizado com o M edicinische Politizei de Frank, pelo qual tinha grande respeito, complementando-o graças ao seu esforço de encorajar a aplicação do conhecimento sócio-médico disponível em sua época". Tratava-se de um código de saúde de caráter abrangente eque dava grande ênfaseà educação. De fato, [...] A primeira lei do código, tratando dos deveres de um oficial de saúde, propunha que este oficial agisse nos colégios, instruindo tanto as crianças quanto os professores a respeito da manuten ção e promoção da saúde. Além disso, 0 oficial de saúde devia esclarecer 0 adolescente a respeito dos excessos sexuais ${ }^{1}$.
Há de se considerar que, na prática, o referido código proposto por $M$ ai não chegou a vigorar plenamente em face de questões de ordem tanto econômica quanto política. Como já foi exposto, na Europa, o primeiro país a institucionalizar a polícia médica- que, dentremuitoscampos deatuação, exerceu influência também sobre a saúde escolar -, foi a Alemanha. M as as idéias do Sistema Frank logo se difundiram por todo 0 continenteeuropeu eos Estados Unidos daAmé rica: [...] Em 1779, os volumes deste trabalho enciclopédico começaram a ser lançados, provocando, em muitas direções, um impacto evidente. $\mathrm{N}$ aturalmente, este efeito foi sentido com maior intensidade na área de língua germânica e em áreas, como a Itália, que estavam em contato estreito, tanto político quanto cultural, como os Estados alemães. Entretanto, não se pode negar a importância de Frank na difusão do termo e da idéia de "polícia médica" não somente na Alemanha, Áustria e I tália, mas também na França, Grã-Bretanha e Estados Unidos. Na verdade foi usado na Itália, até $1890^{1}$.

No Brasil, pontua M oncorvo Filho ${ }^{3}$, os primeiros estudos sobre saúde escolar se deram a partir de 1850. Lima² observa, no entanto, que embora um decreto do Barão do Lavradio, em 1889, tratasse de regulamentar a inspetoria das escolas públicas e privadas da Corte, de fato, a questão da higiene escolar somente ganhou impulso, no país, a partir do início do século XX. Naquele contexto histórico-social, marcado pela intensa imigração - essencial à expansão da cafeicultura -, o país vivenciava uma crítica situação de saúde pública. A varíola - uma doença atualmente erradicada em todo o mundo - , era um grande problema para a saúde pública e epidemias de cólera e peste bubônica comprometiam as atividades de comércio exterior do país. A isso se somava uma epidemia de febre amarela urbana e a alta incidência de doenças ainda hoje comuns à realidade brasileira, tais como malária, sífilis, tuberculose e hanseníase. Tal quadro nosológico tinha como tradução uma alta mortalidade da população em geral, obviamente agravada nas crianças, vitimizadas também pela desnutrição, por diarréias ou por doenças hojeimunopreveníveis, tais como sarampo, tétano, coqueluche edifteria.

$\mathrm{Na}$ avaliação de Lima², a saúde escolar - ou higiene escolar - , como então usualmente era denominada, se deu na intercessão de três doutrinas: a da polícia médica, a do sanitarismo e a da puericultura. 0 termo "polícia médica" aqui utilizado tem a sua gênese no grego "politéia" e 
está relacionado a uma teoria prática e administrativa do estado absolutista alemão. Assim posto, $\mathrm{N}_{\text {ovaes }}{ }^{4}$ avalia que a polícia médica foi o mecanismo através do qual o Estado assumiu a função de zelar pela saúde da população, cabendo aos médicos não somente a responsabilidade de tratar os doentes mas, também, controlar todos os aspectos da vida dos indivíduos.

Para Lima², na saúde escolar, o exercício da polícia médica "se deu pela inspetoria das condições de saúde dos envolvidos com o ensino"; 0 sanitarismo, "pela prescrição a respeito da salubridade dos locais de ensino" e a puericultura, "pela difusão de regras de viver para professores e alunos...."

No transcorrer do século XX, a saúde escolar no Brasil experimenta avanços em sintonia com a evolução técnico-científica, deslocando o discurso tradicional - de lógica biomédica - , para a concepção da estratégia Iniciativa Regional Escolas Promotoras de Saúde (IREPS), um discurso de múltiplos ol hares que surge no final da década de oitenta, "como parte das mudanças conceituais e metodológicas que incorporam o conceito de promoção de saúde na saúde pública, estendendo-o ao entorno escolar" 5 .

O conceito de promoção da saúde, no qual se baseia a IREPS, foi cunhado a partir da Carta de Ottawa como o processo destinado a capacitar os indivíduos para exercerem um maior controle sobre sua saúde e sobre os fatores que podem afetá-la, reduzindo os fatores que podem resultar em risco efavorecendo os que são protetores esaudáveis. Segundo tal concepção, [...] É essencial proporcionar meios para que, ao longo de sua vida, a população se prepare para as diferentes etapas da mesma e enfrente as enfermidades e lesões crônicas. Isto só será possível através das escolas, lares, lugares de trabalho e ambiente comunitário, no sentido de que exista uma participação ativa por parte das organizações profissionais, comerciais e beneficentes, orientada tanto ao exterior com ao interior das próprias instituições ${ }^{6}$.

$\mathrm{Na}$ opinião de $\mathrm{Harada}^{7}$, ao adotar a estratégia IREPS, "a saúde escolar passa, necessariamente, por uma revisão de seu conceito e de sua prática higienista eassistencialista" e, desta forma, "tem a possibilidade de avançar e ampliar a sua concepção e práticas com uma visão integral einterdisciplinar do ser humano, dentro de um contexto comunitário, ambiental e político mais amplo".
Iniciativa Regional Escolas Promotoras de Saúde (IREPS)

Desde 1995, a Organização Pan-Americana de Saúde (OPAS) tem estimulado a IREPS com o objetivo de fortalecer a capacidade dos países da América Latina e do Caribe na área de saúde escolar. A implantação de escolas promotoras de saúde implica um trabalho articulado entre a educação, a saúdee a sociedade demanda a ação protagonista da comunidade educativa na identificação das necessidades e dos problemas de saúde e na definição de estratégias e linhas pertinentes para abordá-los e enfrentá-los. Trata-se de uma estratégia de promoção da saúde no espaço escolar com enfoque integral, tendo três componentes relacionados entre si, a saber:

1) Educação para a saúde com enfoque integral, incluindo o desenvolvimento de habilidades para a vida;

2) Criação e manutenção de ambientes físicos e psicossociais saudáveis e,

3) Oferta de serviços de saúde, alimentação saudável e vida ativa.

$\mathrm{Na}$ avaliação de Ippolito-Shepherd ${ }^{5}$ a escola promotora de saúde é a instituição educacional que:

Implementa políticas que:

- A póiem a dignidadee o bem estar individual e coletivo;

- O fereçam múltiplas oportunidades de crescimento e desenvolvimento para crianças e adolescentes.

Implementa estratégias que fomentam e apoiam aprendizagem e saúde:

- Permitindo a participação dos setores saúdee educação, da família e da comunidade;

- Oferecendo educação para saúde em forma integral etreinamento em habilidades para a vida;

- Reforçando os fatores de proteção e de diminuição de risco;

- Permitindo o acesso aos serviços de saúde, nutrição e atividade física.

Envolve todos os membros da escola e da comunidade:

- Na tomada de decisões

- Na execução das decisões.

Tem um plano de trabalho para:

- M elhorar o ambiente físico e psi cossocial;

- Criar ambientes livres de fumo, drogas, abusos e qualquer forma de violência;

- Garantir 0 acesso a água limpa e instalações sanitárias;

- Possibilitar a escolha de alimentos saudáveis;

- Criar um ambiente escolar saudável; 
- Promover atividades que se estendam para fora da escola.

Implementa ações que conduzam a melhorar a saúde de seus membros e trabal ha com os lideres da comunidade para assegurar:

- Acesso à nutrição;

- Atividade física;

- Condições de higi ene e limpeza;

- Serviços de saúde e respectivos serviços de re ferência.

Oferece treinamento efetivo a professores e educadores

Tem Comissão Local de Educação e Saúde:

- Associação de pais;

- Organizações não governamentais;

- Organizações comunitárias.

Segundo a avaliação de Silva et al. ${ }^{8}$, a Escola Promotora de Saúde se traduz como importante estratégia para uma cidade mais saudável, numa ótica deinclusão eparticipação. Assim posto, [ ...] como espaço de referência para a comunidade, representada por familiares, responsáveis, profissionais de educação e outros, a escola pode exercer um papel protagonista de práticas educativas na intercessão com outros equipamentos sociais, entre os quais se destacam, nessa iniciativa, os serviços de saúde e, particularmente, a pediatria 8 .

Os referidos autores ainda nos alertam que "as práticas educativas em saúde não se restringem ao profissional de saúdee aos serviços de saúde, mas devem ter neles o seu lócus"8. No entanto, os mesmos advertem que tais práticas devam ser construídas junto com os educadores e inseridas no projeto político pedagógico da escola.

\section{O lugar da atenção à saúdena educação básica}

U sualmente, os técnicos da área de saúde têm compreendido a educação em saúde na escola como intervenções pontuais, a respeito de conteúdos afeitos a questões nosológicas do momento. Técnicos desaúdefalam, por exemplo, dedengue na escola para crianças eadolescentes porque uma epidemia de dengue assola a sociedade. Trata-se, a nosso ver, de uma intervenção, no mínimo, equivocada, visto que, conforme preconizam os parâmetros curriculares nacionais (PCN), os conteúdos de saúde devem comparecer no currículo da formação de crianças eadolescentes como uma abordagem transversal einterdisciplinar: tais conteúdos constituem objeto da atenção de todos os níveis e séries escolares, integrados a todas as disciplinas como um discurso cotidiano do processo ensino/aprendizagem? ${ }^{9}$
No entanto, a relação entre a Saúde e Educação, no quediz respeito à saúdeescolar, nem sempre tem sido harmoniosa. Quando pensada numa perspectiva exclusivamentemédica efocalizada no controlee prevenção de doenças, a educação em saúde tem sido pouco efetiva para provocar mudanças de atitudes que levem a opções mais sau dáveis de vida. A este respeito, Cerquei$\mathrm{ra}^{10}$ pontua que [...] a escola, na maioria dos casos tem sido lugar deaplicação de controlee prevenção de doenças, porque o setor saúde costuma ver a escola como um lugar onde os alunos seriam um grupo passi vo para a realização de ações de saúde. Os professores frequentementesequeixam de queo setor saúde usa a escola e abusa do tempo disponível com ações isoladas que poderiam ser mais proveitosas, com um programa mais participativo e protagonista de atenção à saúde" ${ }^{\prime 10}$.

De acordo com os referidos PCN, através do trabalho rotineiramente realizado pelos professores e especialistas em educação do nosso país, os educandos - dentre muitas outras habilidades - deveriam ser capazes de situar-se no mundo como cidadãos conscientes de seus direitos e deveres políticos, civis e sociais, capazes de adotar no dia-a-dia atitudes de solidariedade, cooperação e repúdio às injustiças e que, especificamente em relação à saúde, estejam aptos a "conhecer o próprio corpo e dele cuidar, valorizando e adotando hábitos saudáveis como um dos aspectos básicos da qualidade de vida e agindo com responsabilidade em relação à sua saúde eà saúde coletiva" $"$.

Assim posto, em vez de ações pontuais e isoladas, a melhor contribuição que a saúde poderia oferecer à educação residena possibilidade de uma ação integrada e articulada, que de maneira crítica e reflexiva possa significar oportunidade de atualização dos educadores, capacitando-os para a tarefa de ministrar o discurso sobre orientação à saúde de forma transversal e interdisciplinar na escola. Outra relevante participação dos técnicos de saúde se justifica na dinâmica escolar do ensino básico, fomentando junto à associação de pais a criação de comissões locais de educação e saúde que dêem conta de interagir junto ao núcleo familiar e comunitário na criação de condições favoráveis da qualidade de vida da comunidade adscrita ao entorno escolar. Soma-se a isso, por fim, a atenção integral à saúde de cada um dos educandos.

Todas as ações anteriormente descritas passam a constituir, na atualidade, as diretrizes da nova política de atenção à saúde do escolar no Brasil. Nesse sentido, foi instituído em todo o 
território nacional o Decreto no 6.286, de 5 de dezembro de 2007, que cria o Programa Saúde na Escola (PSE), e dá outras providências ${ }^{11}$.

Trata-se de um programa cuja finalidade é "contribuir com a formação integral dos estudantes da rede pública de educação básica por meio de ações de prevenção, promoção e atenção à saúde" ${ }^{\prime 11}$ e que visa promover a saúde e a cultura da paz; articular as ações do Sistema Único de Saúde (SUS) às ações da educação básica pública; contribuir para a constituição de condições para a formação integral de educandos; contribuir para a construção de sistema de atenção social, com foco na promoção da cidadania e nos direitos humanos; fortalecer o enfrentamento das vulnerabilidades no campo da saúde eque comprometem o desenvolvimento escolar; promover a intercomunicação escola/saúde e fortalecer a parti cipação comunitária nas políticas de educação básica e saúde ${ }^{11}$.

Em fina sintonia com o paradigma de saúde vigente, o PSE deverá ser implementado com a participação efetiva das equi pes de Estratégia em Saúde da Família, respeitando-se todos os princípios do SUS. Dessa forma, as ações em saúde previstas no âmbito do PSE, a serem desenvolvidas em articulação com a Saúde e a Educação, deverão considerar a integralidade dos educandos, o que significa garantir a cada um deles 0 direito à avaliação clínica, oftalmológica, auditiva, psicossocial, saúde e higiene bucal, avaliação nutricional, promoção da alimentação saudável, bem como 0 acesso a ações educativas que Ihes garantam educação permanente em saúde- aqui incluídas a atividade física e saúde -, através de uma cultura da prevenção no âmbito escolar. Dessa forma, a Saúde e a Educação Básica integradas deverão oferecer à criança eao adolescente escolarizados uma tutoria de resiliência que Ihes confira proteção contra a dependência química, o risco decâncer, acidentes eviolência, doenças sexualmente transmissíveis/aids, gravidez e doenças crônicas ${ }^{11}$

\section{Consideraçõesfinais}

Entendida, de início, como uma prática que se situava na intercessão da polícia médica, do higienismo e da puericultura, a atenção à saúde escolar evoluiu em fina sintonia com o conceito de promoção da saúde. Especificamente no espaço latino-americano e caribenho, a OPAS recomenda este paradigma como forma - principalmente - de subsídio à superação de problemas de saúde da população infanto-juvenil. Há de se considerar, no entanto, que a atuação da promoção de saúde escolar - na perspectiva da supervisão à saúde - , supera os limites desse grupo humano, ocupando-se também da família, do espaço físico escolar e dos profissionais que fazem a educação, numa perspectiva de assistir e também capacitar os indivíduos para um modelo de vida cada vez mais saudável.

No tocante à realidade brasileira, especificamente no que diz respeito à educação em saúde na escola, entendemos ser necessário ao profissional de saúde sensível à questão de planejar/implementar/avaliar tais ações junto com os educadores, além do domínio da IREPS enquanto estratégia, ter um olhar crítico da estrutura efuncionamento do ensino básico. Nessa perspectiva, se inserem as recomendações dos Parâmetros Curriculares $\mathrm{N}$ acionais ${ }^{9}$, ao prescreverem os temas afeitos à saúde como transversais e interdisciplinares, portanto como um discurso do cotidiano escolar, a ser feito pelos educadores, sob múltiplos olhares.

Assim, cabe aos protagonistas da saúde entender que a participação dos mesmos no processo de educação em saúdena escola só se justifica se implementado, menos como ações pontuais de educação à saúde na escola, porém, na potencialização da ação do educador em sala de aula - o que se dá através da oferta de cursos de formação continuada ou atualização voltada para os mesmos.

No entanto, conforme recomenda o PSE, as equipes de saúde da família deverão realizar visitas periódicas epermanentes às escolas, no sentido de avaliarem as condições de saúde dos educandos, proporcionando, dessa forma, 0 atendimento à saúde ao longo do ano letivo, conforme as necessidades locais. 


\section{Colaboradores}

TAM Figueiredo, VLT Machado e MMS Abreu participaram igualmente da concepção do artigo. TAM Figueiredo redigiu a primeira versão do artigo, a qual recebeu contribuições dos outros autores. Todos os autores revisaram e aprovaram a versão final.

\section{Referências}

1. Rosen G. Da polícia médica à medicina social: ensaios sobre a história da assistência médica. Rio de Janeiro: Graal; 1979.

2. Lima GZ. Saúde escolar e educação. São Paulo: Cortez; 1985.

3. Moncorvo Filho CAA. Higiene escolar: seu histórico no Brasil. In: Anais do Primeiro Congresso M édico Paulista. Vol. 3 São Paulo: Seção de Obras d'O Estado de São Paulo; 1917. p. 141-153.

4. Novais HMD. A puericultura em questão [dissertação]. São Paulo (SP): Faculdade de M edicina, Universidade de São Paulo; 1979.

5. Ippolito-Shepherd J. A promoção da saúde no âmbito escolar: a iniciativa regional escolas promotoras de saúde. In: Sociedade Brasileira de Pediatria. Escola promotora de saúde. Brasília: Sociedade Brasileira de Pediatria; 2003.

6. Carta de Ottawa sobre a promoção da saúde, 21 de novembro de 1986. [acessado 2006 mar 18]. Disponível em: http://www.saudeemmovimento.com.br

7. Harada J. Introdução. In: Sociedade Brasileira de Pediatria. Escola promotora de saúde. Brasília: Sociedade Brasileira de Pediatria; 2003.

8. Silva CS. Escola promotora de saúde: uma nova forma de fazer saúde escolar. In: Lopez FA, Campos Junior D. Tratado de pediatria. Barueri: Manole; 2007.

9. Brasil. Secretaria de Educação Fundamental. Parâmetros curriculares nacionais: terceiro e quarto ciclos: apresentação dos temas transversais. Brasília: MEC/ SEF; 2001.

10. Cerqueira MT. A construção da rede Latino Americana de escolas promotoras de saúde. In: Brasil. M inistério da Saúde. Escolas promotoras de saúde: experiências no Brasil. Brasília: Ministério da Saúde; 2007.

11. Brasil. Presidência da República. Casa Civil. Subchefia para Assuntos Jurídicos. Decreto no. 6.286, de 5 de dezembro de 2007. Brasília: Casa Civil, 2007. [acessado 2008 abr 15]. Disponível em: http:/ /www.planalto.gov.br/ccivil_03/_Ato2007-2010/ 2007/Decreto/D 6286.htm

Artigo apresentado em 12/05/2008

Aprovado em 10/11/2008

Versão final apresentada em 22/11/2008 